\title{
STUDENTS' PERCEPTIONS ON CADAVERIC PAINTING AS A METHOD FOR LEARNING SURFACE ANATOMY
}

\section{Uma SV.}

Associate Professor, Department of Anatomy, Sapthagiri Institute of Medical Sciences and Research Centre, No.15, Chikkasandra, Hesarghatta Main Road, Bangalore, Karnataka, India.

\section{ABSTRACT}

Background: Surface anatomy has become very important in anatomy education in the recent decades. The main reason is that surface anatomy forms an obvious connection between basic gross anatomy and clinical practice, as it is the basis for physical examination. Learning methodologies used for surface anatomy includes practicing with cadavers, body painting, peer examination, living anatomy model etc. Live Body painting is an efficient learning tool which mainly helps the visual and kinesthetic learners. It also makes the students relaxed to have a fun filled way of learning which provided some relief to the students from text books. Due to various ethical, cultural and religious reasons live body painting could not be done for all regions in our setup, hence it has been modified as a cadaveric painting in the study. Earlier the method of learning the surface anatomy on cadavers required the student to put in lot of efforts on memorizing the landmarks by surrounding the cadaver during the surface anatomy classes. The aim was to introduce the cadaveric painting to learn surface anatomy which forms the basis for physical examination in clinical practice.

Objectives: To evaluate the students' feedback concerning their perception on the various aspects of cadaveric painting as a mode of learning surface anatomy and to evaluate the difference in the marks obtained by these students in surface marking in III internal( participated in cadaver painting) and those who haven't participated in the study

Materials and methods: Eighty four, first year MBBS students were selected on voluntary basis to do cadaveric painting for the surface marking learning activity of abdominal region.Anonymous feedback regarding their perception of various aspects of cadaveric painting as a mode for learning surface anatomy through questionnaire was done. The mean rating for each item was calculated.Analysis done with SPSS version 16

Results: Majority of students were positive about using cadaveric painting for surface anatomy. Ninety three percent felt it was a powerful learning, $100 \%$ felt it motivated, and helped during exams. There was a significant difference in marks between the groups

Conclusion: Students perceived that cadaveric painting promoted meaningful learning and understanding of surface anatomy.

KEY WORDS: Anatomic body painting, surface anatomy,learning surface anatomy.

Corresponding Author: Dr.Uma S.V, Associate Professor, Department of Anatomy, Sapthagiri Institute of Medical Sciences and Research Centre, No.15,Chikkasandra, Hesarghatta main road, Bangalore-560090, Karnataka, India. Ph-0091-80-22188700/03 -0091-9986018610

Fax-080-28393404E-Mail: drsvuma@gmail.com

Access this Article online

Quick Response code

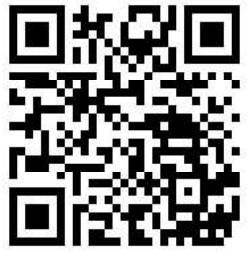

DOI: 10.16965/ijar.2020.165

\begin{tabular}{|c|c|c|}
\hline \multicolumn{3}{|c|}{ Journal Information } \\
\hline \multicolumn{3}{|c|}{$\begin{array}{c}\text { International Journal of Anatomy and Research } \\
\begin{array}{c}\text { RG Journal } \\
\text { Impact: } 0.21^{*}\end{array} \\
\text { ISSN (E) 2321-4287 | ISSN (P) 2321-8967 } \\
\text { https://www.ijmhr.org/ijar.htm }\end{array}$} \\
\hline \multicolumn{3}{|c|}{ Article Information } \\
\hline $\begin{array}{l}\text { Received: } 10 \text { May } 2020 \\
\text { Peer Review: } 11 \text { May } 2020 \\
\text { Revised: None }\end{array}$ & $\begin{array}{l}\text { Accepted: } 21 \text { May } \\
\text { Published (O): } 05 \\
\text { Published (P): } 05\end{array}$ & $\begin{array}{l}20 \\
2020 \\
2020\end{array}$ \\
\hline
\end{tabular}

North America. J.W. Op Den Akker et al published the first scholarly article detailing the use of $A B P$ as an anatomic educational tool in 2002 in
Anatomic Body Painting (ABP) originally emerged as a branch of artistic body painting outside of 
Netherlands [1]. It described the technique as "a successful and enjoyable means of teaching various aspects of anatomy in relation to physical examination [2]. The three main modalities of living anatomy are surface anatomy, medical imaging, and surgical procedures. The students are able to engage in self-directed learning (SDL), leading to active anatomy education outcomes[3].Body painting, a form of body art where the human skin is painted, has been reported as a useful adjunct to living anatomy, traditional anatomy courses, and clinical skills classes [4].This technique of ABP to teach the anatomy of several structures like muscles, vessels, bones, nerves, and internal organs, allows for easy palpation and physical examination in clinical practice [5].

Medical students reported that they were engaged during the body painting session and had fun which helped in long term retention of anatomical knowledge[6]. Following the work of Op Den Akker (2002), this was used by Finn et al., where body painting of realistic projections of internal organs was done onto the surface of the body [4]. This had the unexpected benefit of increasing body confidence on peer examination by providing a fun experience and therefore this $A B P$ was made as a session in the introductory event in the peer examination classes. The colorful visual images of various structures which were obtained after the painting exercises, were found to increase the students' memory [5]. Literature has suggested the usefulness of body painting and clay modelling in increasing student engagement as well as consolidation of anatomy. Nicholson etal., demonstrated that these learning tools would be valuable for healthcare students whose preferred learning style involving visualisation and kinaesthesis [7]. Painting the lungs on the body surface allowed students to percuss (tap) the thorax to identify the difference in sounds during inhalation and exhalation, providing students with a clear mental image of precisely what was involved. With regard to referred pain, painting the source of the pain, and the referral site, in the same vivid colour, provided an unforgettable way to remember the relationship $[8,9]$, So this painting exercise for the students was done as a learning tool for surface anatomy.
In a study by Natalie, twenty six anatomists participated worldwideand critically analysed, the efficacy of body painting, the promotion of knowledge retention and recall and the considerations and practicalities regarding the use of body painting as a teaching tool. They concluded that body painting helped in promoting knowledge retention and recall, particularly learning through the process of cognitive load due to combining the use of color and kinesthetic learning with anatomical theory [10]. Overall the anatomists appreciate body painting as an effective, enjoyable, engaging and cost efficient adjunct to the multimodal anatomy curriculum [10]

Surface anatomy is defined as the anatomical structures or features that are identifiable on the outside of the body as surface projections [11] These might include, for example, bony landmarks any structure or musculature. An understanding of the surface anatomy and markings of the body is imperative when introducing clinical sciences. "Living Anatomy" authored by Burns and Colenso, which was the collection of 12 male and 8 female illustrations, depicting muscles painted on the body, were used in different actions and activities like kneeling, boxing, rowing, fencing, dancing and running were also used for teaching[12]. Ganguly [13] describes an obvious connection formed between basic gross anatomy and clinical practice through surface anatomy, as it is the basis of physical examination [14].

The medical council of India ( $\mathrm{MCl}$ ) in its ' $\mathrm{V}$ ision 2015' document also emphasized the need for early clinical exposure (ECE)[15]. This document recommended increase in use of active methods of learning such as group discussion, seminars, role play, field visits, demonstrations, peer interactions etc. which would enable students to be a competent Indian medical graduate[15].

Surface Anatomy, even though it is important for clinical examination of patient like palpation of abdominal organs, hearing the respiratory sounds in various parts of lungs, hearing the heart sounds in various areas, Students don't realize its importance in the first year. The students generally find it difficult to memorize the landmarks for surface anatomy. The challenge faced by anatomist is to teach more anatomy in 
less time available, so we must take innovative steps where we can provide opportunities for students to learn anatomy actively with a clinical base and fun filled manner so retention will be there for a longer time. With this background the aim of the study was to introduce cadaveric painting as a mode of learning surface anatomy which forms the basis for physical examination in clinical practice and the objectives were to evaluate the students' feedback concerning their perception on the various aspects of cadaveric painting as a mode of learning surface anatomy and to evaluate the difference in the marks obtained by these students in surface marking in III internal (participated in cadaver painting) and those who haven't participated in the study.

\section{MATERIALS AND METHODS}

After obtaining ethical clearance from the institutional ethical review board the study was conducted on first year MBBS students. Eighty four of 150 first year MBBS students (forty eight male and andthirty six female students) volunteered for the study. They were divided into six groups of fourteen in each. Students were assigned a cadaver to do painting for the surface marking learning activity of abdominal region.They were free to choose the organ /structure for surface marking and plan and prepare among themselves, for which one day was given.They were free to choose acrylic or poster colours and in the presence of the facilitator the students did a team work of cadaveric painting (Figure 1) within a time interval of one hour and then all these student demonstrated their structure's surface marking to other students.
Anonymous feedback was obtained from the students regarding their perceptions about the various aspects of cadaveric painting after a month, as they completed their internal assessment. The questionnaire has eight items using the likert five-point grading scale. The items were developed based on previous literature[5]. Pilot testing of the questionnaire was done on the first group of students. The reliability of the questionnaire was found to be satisfactory (Cronbach's alpha of 0.70). The proportion of students who responded in each category for each item was tabulated (Table 1)

The marks obtained in surface marking (out of ten marks) in their third internals by fifty students selected randomly among who participated in the study were compared with that of other fifty students who did not participate in the study, after one month of completion of the cadaveric painting activity. Analysis was done using SPSS version 16.

\section{RESULTS}

All eighty four completed the questionnaire. Table 1 summarizes the responses of the students. It was noted that except item no $7,85 \%$ to $99 \%$ of students either agreed or strongly agreed to each of the statements in the questionnaire. Four $(1,2,5,6)$ of the statements showed agreement levels of over $92 \%$. Three of the statements $(3,4,8)$ showed agreement levels between $80 \%$ and $90 \%$. Item no 7 shows $50 \%$ of agreement levels and $35 \%$ disagreement levels. The mean score of Non-painting group of fifty was $4.53 / 10$ and the mean score of painting group of fifty was $7.07 / 10$. There was a significant difference between the two groups with a $p$ value of 0.001 .

Fig. 1:Cadaveric body painting of structures in the abdomen region.

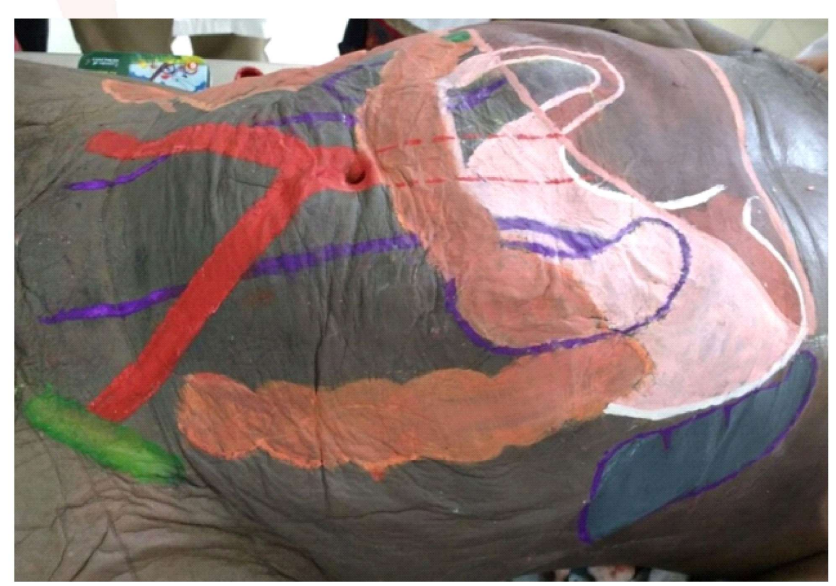

Figure showing the surface markings of stomach, liver, spleen, kidney, ureter, abdominal aorta and inguinal canal 
Table 1: Results of the Feedback Questionnaire.

\begin{tabular}{|c|c|c|c|c|c|c|}
\hline Q.No & Question & $\begin{array}{l}\text { Strongly } \\
\text { Agree (\%) }\end{array}$ & Agree (\%) & $\begin{array}{l}\text { Neutral } \\
(\%)\end{array}$ & $\begin{array}{l}\text { Disagree } \\
(\%)\end{array}$ & $\begin{array}{c}\text { Strongly } \\
\text { Disagree (\%) }\end{array}$ \\
\hline 1 & $\begin{array}{l}\text { Painting anatomical structures on to the surface of the skin is a } \\
\text { powerful method of learning surface anatomy. }\end{array}$ & $78(92.85)$ & - & $6(7.14)$ & - & - \\
\hline 2 & Did this session stimulate your interest in surface anatomy? & $54(64.28)$ & $30(35.71)$ & - & - & - \\
\hline 3 & Session were interactive & $60(71.42)$ & $12(14.28)$ & $12(14.28)$ & - & - \\
\hline 4 & $\begin{array}{l}\text { Do you think this approach is useful as an aid for learning the } \\
\text { clinical relevance of anatomy? }\end{array}$ & $54(64.28)$ & $18(21.42)$ & $12(14.28)$ & - & - \\
\hline 5 & Promoted team based /peer learning & $48(57.14)$ & $30(35.71)$ & $6(7.14)$ & - & - \\
\hline 6 & $\begin{array}{l}\text { Helped in recollecting the surface markings during the internal } \\
\text { exam }\end{array}$ & $42(50)$ & $42(50)$ & - & - & - \\
\hline 7 & $\begin{array}{l}\text { Would have volunteered as a model for live body painting of } \\
\text { abdominal surface marking }\end{array}$ & $24(28.57)$ & $18(21.42)$ & $12(14.28)$ & $24(28.57)$ & $6(7.14)$ \\
\hline 8 & Cadaveric painting to be continued for further batches & $72(85.71)$ & $12(14.28)$ & - & - & - \\
\hline
\end{tabular}

Table 2: Comparisons of results of our study with other studies $[5,18,19,21]$.

\begin{tabular}{|c|c|c|c|c|c|c|}
\hline S.no & Questions & $\begin{array}{c}\text { Komala N } \\
2012[5] \\
\text { physiotheraphy+dental } \\
\text { students ( } n=85) \%\end{array}$ & $\begin{array}{c}\text { Pitchanee } \\
\text { Thailand } \\
2016[18] \\
\text { MBBS } \\
(n=48) \%\end{array}$ & $\begin{array}{l}\text { Paul Mc. Menamin } \\
\text { Australia } \\
2005 \text { [19] } \\
\text { MBBS cohort } \\
(n=176) \%\end{array}$ & $\begin{array}{l}\text { Amy et al } 2009[21] \\
\text { Washington } \\
\text { Speech and hearing } \\
\text { students } \\
(n=111) \%\end{array}$ & $\begin{array}{c}\text { Present study } \\
\quad(n=84) \%\end{array}$ \\
\hline 1 & $\begin{array}{l}\text { Body painting sessions were interesting \& } \\
\text { enjoyable }\end{array}$ & 98.7 & 83 & 73 & 78 & 99.99 \\
\hline 2 & Body painting sessions were interactive & 98.7 & 92 & - & - & 85.7 \\
\hline 3 & $A B P$ is a useful tool to learn surface marking & 96.1 & 83 & 59 & 96 & 92.85 \\
\hline 4 & To be continued for further dissections & - & 79 & - & - & 99.99 \\
\hline 5 & Retention is good & 98.7 & - & - & - & 100 \\
\hline
\end{tabular}

\section{DISCUSSION}

The cadaveric painting method which was used to learn the surface and the clinical anatomy was well accepted by our students as an effective method to learn the surface anatomy and its clinical relevance. The visual images increased their memory of the landmarks. The students also commented that the use of painting while they learned from a text, required a lot of concentration and understanding and this transferring of the knowledge into paintings helped them in deep understanding as well as retaining the gained knowledge over a longer period of time.Our study was compared to other studies and is summarized in Table 2.

One hundred and thirty-three preclinical medical students participated in 24 focus groups at Durham University. Focus groups were conducted to ascertain whether or not the medical students found the body painting of the anatomical structures to be an educationally beneficial learning activity. The data were analyzed and five principal themes emerged: body painting as a fun learning activity, body painting as promoting the retention of knowledge, the factors which contributed to the memorability of the body painting, removal from the comfort zone, and the impact of the body painting on the students' future clinical practice [4].Our study also revealed almost the same effects like the students found this an enjoyable and fun filled with lot of interaction between peer group and also accepted this not only as a tool to learn surface anatomy but also wanted this activity to be continued for the future batches too.

Komala, studied body painting exercises for the students to learn the surface anatomy of certain regions in physiotherapy and dental students[5].This study concluded with the result as $98.7 \%$ of the students agreeing that the body painting method of learning the surface marking was interesting. $98.7 \%$ agreed that they actively participated in the body painting sessions. 96.1\% felt that painting on each other 
facilitated a peer to peer learning and $90.9 \%$ agreed that body painting gave them the feel of the landmarks and various structures[5]. 98.7\% felt that the retainment of knowledge was better when it was learnt through body painting. These results were almost similar to our study (Table 2) Claudia Diaz, James Cook University opined body painting has become the most popular technique, as it is a very engaging way for students to learn anatomy and he developed the "Anatomical Man/Woman" projects where student artists and photographers fully body painted student models and enthused their Prime Minister to such an extent that she body painted with them during her visit. She found the experience "a very innovative and entertaining demonstration." The Anatomical Man projects both inspired and enthused students immensely as they witnessed how engaging and beautiful anatomical body painting can be. [16].The 2010 survey found $83 \%$ of health science students thought practical, innovative approaches like body painting assisted their deeper understanding of anatomy, 81\% thought they assisted their long-term memory of anatomy, and $82 \%$ reported that the learning and memory skills they acquired in anatomy have been useful in other clinical subjects[16].

Bennet in his study with physician assistant programmed students, found anatomy to be a challenging subject tried ABP sessions typically scheduling sessions for a 3-hour block of time after they have completed an anatomic region. Students were divided into teams of three or four with the guideline that each team should have at least one "canvas," one painter, and one researcher. For example, one topic might be "paint all the structures that are important to understand when one is performing a cricothyrotomy," or "paint the brachial plexus and be able to demonstrate the causes of an upper plexus injury and a lower plexus injury"[2]

The session concludes with group presentations of their work, including explanations about the development of the structures depicted, their function, and potential pathophysiology. This resulted in a new level of achievement among the student groups and gave students new insight into how to approach human anatomy[2] . Fifty second year medical students were engaged in a painting session where the surface markings of the lungs, liver and heart on the thoraces of their consenting peers were done. These sessions were uniformly enjoyed by students, with significant improvement in their mean confidence for clinical examination skills and surface anatomy knowledge. Moreover, students found the session highly useful and derived a lot of pleasure form the experience[17].

In a study on pre clinical students of 48 control and 48 experimental group, the group who were engaged in painting the muscles, nerves and vessels of hand were evaluated for short-term and long-term retention of knowledge using a set of multiple-choice questions immediately after the body painting exercise and 1 month after the exercise, respectively. Analysis of the results showed that the mean scores of control and experimental, there was no significant difference between the scores for each group both immediately after and at 1 month after the experiment[18].

Of the 120 responded in 2007 batch, around 65\% found the sessions both enjoyable and a valuable learning tool which is slightly higher than the 2005 cohort (Table2) who had less extensive use of the method of teaching and who did not use the method in potentially sensitive body areas such as femoral triangle and upper torso. Learning is supported through a variety of means. At the neurological level, the act of body painting, is encoded by the brain through multiple modalities like, reading and reflecting on the anatomy instructional text, and then implementing it through haptic movements; the use of active colour as a signifier and through sensation as in 'experienced touch'. Information more encoded is also retrievable[19].

In a study in Spain ,189 first-year medical students enrolled to do the body painting as an alternative tool for learning surface and clinical anatomy [20]. All most all the participants recommended this activity for classmates in future courses as in our study. The students when asked about volunteering themselves as model for body painting activities around 35\% disagreed due to their inhibition and shyness. Hence in future planned for a live body painting activity with tight-fitting clothes on them to over- 
come the embarrassment of the students.

Limitations of the study are the sample size is small-being a pilot study. It was done only for abdominal region there would be differences if done for other regions and the results would be influenced by voluntary participation and on gender basis too as 48 boys and 36 girls took part in the study. Moreover it is a time consuming activity.

\section{CONCLUSION}

The cadaveric painting activity was successful in achieving its objectives. The students felt that the body painting method was fun and lots of peer learning happened. While doing body painting, they could actually get the feel of and the relationships between the various anatomical structures. It is clear that use of art in medical education is a highly memorable tool for learning also. When used along with dissection in anatomy classes, these innovative approaches appear to provide motivation that leads to deeper learning.

\section{ACKNOWLEDGEMENTS}

I would like to acknowledge our head of the department, my colleagues, helpers and mainly my students who helped me during my study.

\section{Conflicts of Interests: None REFERENCES}

[1]. Op Den Akker JW, Bohnen A, Oudegeest WJ, Hillen B. Giving color to a new curriculum: bodypaint as a tool in medical education. Clin Anat. 2002 Aug;15(5):356-62.

[2]. Bennett C. Anatomic Body Painting/: Where Visual Art Meets Science. J Physician Assist Educ. 2014;25(4).

[3]. Ganguly PK, Chan LK. Living anatomy in the 21st century:how far can we go? South East Asian J Med Educ 2008; 2: 52_7A qualitative study of student responses to body painting

[4]. Finn GM, McLachlan JC. Aqualitative study of student responses to body painting.Anat Sci Educ. 2010 Jan-Feb;3(1):33-8.

[5]. Nanjundaiah K, Chowdapurkar S. Body-painting: A tool which can be used to teach surface anatomy. J Clin Diagnostic Res. 2012;6(8):1405-8.

[6]. Finn GM, White PM, Abdelbagi. The impact of color and role on retention of knowledge: a body-painting study within undergraduate medicine Anat Sci Educ. 2011 Nov-Dec;4(6):311-7.

[7]. Nicholson LL, Reed D, Chan C. An interactive, multimodal Anatomy workshop improves academic performance in the health sciences: a cohort study. BMC Med Educ [Internet]. BMC Medical Education; 2016;16(1):7.
[8]. Mclachlan JC. Innovative pedagogies series/ : Done to death. Higher Education Academy, 2015

[9]. McLachlan JC. New path for teaching anatomy: Living anatomy and medical imaging vs. dissection. Anat Rec - Part B New Anat. 2004;281(1):4-5.

[10]. Natalie E. Cookson, Justine J. Aka, Gabrielle M. Finn .An exploration of anatomists' views toward the use of body painting in anatomical and medical education: An international study.https://doi.org/ 10.1002/ase.1698

[11]. Gabrielle M Finn,Current perspectives on the role of body painting in medical education. Advances in Medical Education and Practice 2018:9:701-706

[12]. Asad MR, Nasir N. Role of Living and Surface Anatomy in Current Trends of Medical Education. 2015;(2):203-10.

[13]. Ganguly PK. Teaching and Learning of Anatomy in the 21st Century:Direction and the Strategies. The Open Medical Education Journal.2010;3.

[14]. Sugand K, Abrahams P, Khurana A. The anatomy of anatomy: a review for its modernization. Anat Sci Educ. 2010;3(2):83-93.

[15]. MClBooklet;Vision2015.Availablefrom http:// www.mciindia.org/tools/announcement/MCl booklet.pdf

[16]. Claudia Diaz, For stimulating multidisciplinary first year students to learn Anatomy for life via innovative, pro-active approaches to improve engagement and learning, James Cook University.2011 Citations for Outstanding Contributions to Student Learning

[17]. J Dorgham, J Woodcock, E Grove.Does accurate surface anatomy Body painting increase student's confidence in accurate clinical examinations? An innovative teaching technique.WEMJ Volume 114 No. 1 Article 3 March 2015

[18]. Pitchanee J, Chuchard P, Suchirat B, Paranyu K.Body painting to promote self-active learning of hand anatomy for preclinical medical students.Medical Education Online 2016,21:30833-http://dx.doi.org/ 10.3402/meo.v21.30833

[19]. McMenamin PG,Body painting as a tool in clinical anatomy teaching. Anat Sci Educ. 2008 JulAug;1(4):139-44. doi: 10.1002/ase.32

[20]. Carmen C M, Antonio R G, David AG, Gonzalo PA, Arturo P.The Teaching of Surface Anatomy by Body Painting. Int. J. Morphol. vol.37 no.3 Temuco Sept. 2019 http://dx.doi.org/10.4067/S071795022019000300912

[21]. Washington State University, Department of Speech and Hearing Sciences;2009. Amy SkinderMeredith,Innovative Teaching Activities for AnatomyandNeuroanatomy [https://www.asha.org/ Events/convention/handouts/2009/2105_SkinderMeredith_Amy/].

How to cite this article: Uma SV. STUDENTS' PERCEPTIONS ON CADAVERIC PAINTING AS A METHOD FOR LEARNING SURFACE ANATOMY. Int J Anat Res 2020;8(2.3):7572-7577. DOI: 10.16965/ ijar.2020.165 